\title{
Building Maintenance Strategy: A Sustainable Refurbishment Perspective
}

\author{
Eric Chan \\ Construction and Facilities Management, School of Architecture and Built Environment, Deakin University, Australia \\ *Corresponding Author: eric.chan@deakin.edu.au
}

Copyright $(0) 2014$ Horizon Research Publishing All rights reserved.

\begin{abstract}
The entire life cycle of a building include construction, operation, maintenance, demolition and removal, and the normal expected life span of a commercial building may up to 100 years. During this time span, building refurbishment is an important topical in facilities management but limited attempt has been made to study the sustainable refurbishment. In fact, refurbishment strategy should always be one of the core business decisions in the management agenda. The purpose of this research study is to collect the view from a group of practitioners of Australia prior to deciding the building maintenance strategy of existing commercial building. Through extensive literatures review and the quantitative and qualitative data collecting approaches, this paper concludes that traditional maintenance strategies are not adequate but sustainable approach is the right direction. Along the line, the key factors affecting sustainable refurbishment are economical considerations, and the obvious benefits relates to social matters. Respondents also suggest three precedent strategies in sustainable refurbishments to materialize such benefits: namely reusing building elements, applying sustainable techniques and using new materials and adopting new technologies.
\end{abstract}

Keywords Building Maintenance Strategy, Facilities Management, Sustainable Refurbishment, Commercial Building

\section{Introduction}

Building maintenance is one of the important topical, which has attracted much research attention, in building construction (Amani et al. 2012; Christian \& Pandeya 1997; Fu, Kaya \& Aouad 2007; Kishk et al. 2003; Lai, AW \& Pang 2010; Olanrewaju, Khamidi \& Idrus 2011), and the state of art in maintaining the building facilities sustainably is another hot topic which have been studied in many countries (Fu, Kaya \& Aouad 2007; Kishk et al. 2003; Matthews 2007; Narayan 2012; Róka-Madarász 2011; Yiu 2007) but seldom researched in Australia. In fact, the rapid economic growth during the past decades has resulted in significant increases in the value and number of commercial buildings in Australia (McLean 2012). However, limited attempt has been made to study the sustainable refurbishment of this type of development (Kofoworola \& Gheewala 2008).

The entire life cycle of the building include manufacturing of building materials, construction, operation, maintenance, demolition and removal, and the normal expected life span of a commercial building is 30 years, 50 years to 100 years' time frame upon the completion and occupation (Ding \& Itoh 2002; Rojahn et al. 2011). In order to maintain the usability and efficiency of the building premises, there is a need to be regularly maintained and refurbished. Chanter and Swallow (2008) state that BS 3811 has defined maintenance as " a combination of any actions carried out to retain an item in, or restore it to an acceptable condition". It is contended that maintenance is the work undertaken in order to keep, restore or improve every facility, its services and surrounds to a currently acceptable standard and to sustain the utility and value of the facility. This may include refurbishment to raise the original standards where appropriate. In fact, the ability to upgrade an existing commercial building not only extends its useful life, but is also clearly a more sustainable option than the process of demolition and rebuilt (Bullen 2007). Therefore, the key focus for this paper is to review and study the costs and benefits of sustainably upgrading of existing commercial building stock prior to formulating the overall building maintenance strategy which is an important business decision.

More specifically, the research designs include reviewing existing theories regarding understanding the importance of building maintenance strategy, the effect of sustainable refurbishment and collecting the view from the stakeholders and practitioners in the industry.

\section{Literature Review}

\subsection{Building Maintenance Strategy}

Zawawi et al. (2010) identify factors causing poor 
maintenance in various types of buildings. They are about inappropriate setting up, policies and quality standards; inadequate understanding of occupant satisfaction, insufficient number of staff members and the inefficient strategies used in maintenance delivery. Olanrewaju, Khamidi \& Idrus (2011) suggest that there is a need to develop a performance model for building maintenance in order to add value to the existing facilities. Lee \& Scott (2009) state that maintenance policy is a tool for maintenance personnel to plan their appropriate maintenance strategies. Building maintenance policy is hinged on the three essential elements which are the choice of maintenance strategy, defining maintenance standard and allocation of maintenance resources. Therefore, maintenance and refurbishment strategy should always be one of the core business decisions in the management agenda (Gilpin-Jackson 2010; Wileman 2007). De Marco, Ruffa \& Mangano (2010) has researched to determine the fundamental factors influencing maintenance costs and find that building maintenance cost reduction can only be achieved by making appropriate design decisions on the strategic level. In fact, according to Lee \& Scott (2008), there are strategic and operational factors influencing the management of building maintenance operation and process. These factors include building maintenance policy and strategy, strategic management, facility management and performance management. The management of building maintenance operation processes is the key for providing better built environment to building customers and users. However, maintenance is not always at the top of the priority list in most of the management agenda. This barrier contributes to the gaps between top management at the strategic level and maintenance personnel at the operational level. In fact, building maintenance is in changing pace with the development of facilities management, which impacts on the planning to implementation of maintenance operation processes and building performance. The information related to the strategic and operational factors is essential before an in-depth study is undertaken about the improvement of the gaps between top management at the strategic level and maintenance personnel at the operational level for building operation efficiency.

Therefore, maintenance objective must be one of the organizational sub-business objectives. Planning of maintenance objectives have impacts on the facility management operation in terms of using different maintenance strategies, which are influenced by the cost, quality and process directly and indirectly. Lai (2010) has studied the problems with budget allocation of building operation and maintenance for commercial buildings in Hong Kong. The importance of satisfying facilities management needs is usually recognized but the motivations of practitioners toward preparation of proper budgets are inadequate. Ali et al. (2010) also study the factors affecting housing maintenance cost in Malaysia by surveying the building managers, supervisors and maintenance management staff. Therefore, there is a need to collect the view from the practitioners before deciding the building maintenance strategy and the next step is to access the viable concepts.

\subsection{Sustainable Refurbishment and Stakeholders}

According to BS 3811, building maintenances can be 1.planned: maintenance organized and carried out with forethought to a predetermined plan; 2.unplanned: ad-hoc maintenance carried out to no predetermined plan. These maintenances are mainly corrective or preventive maintenance (Chanter \& Swallow, 2008). The former means "fix it when it breaks", i.e. maintenance is carried out after a breakdown or when an obvious fault has occurred, whilst the latter is performed before facilities failure at a fixed schedule (Tran, Yang, Oh, \& Tan, 2008; Wang, Chu, \& $\mathrm{Wu}, 2007)$. Even though preventive maintenance can retain facilities in good condition and extend their life, the buildings' usability may not be efficient or any value-added if sustainable components have not been considered. In fact, both traditional maintenance strategies may not suffice to fulfill the client and user's needs. The traditional approaches are simply for routine or remedial, or planned and unplanned categories but are clearly of limited value. No matter traditional maintenance actions perform passively after a breakdown or to actively prevent a breakdown, they do not materially enhance the building value. Therefore, strategic sustainable maintenance and refurbishment are required.

In fact, the dimensions of building maintenance include raising the standards, providing sustainable and energy-efficient buildings, providing innovative design solutions, increasing community use of facilities, maximizing value for money, and ensuring efficient and effective management of existing capital assets (Chanter \& Swallow, 2008). Contemporary building maintenance approach must be proactive. Sustainable building refurbishment is driven by the market and legislation. With a focus on energy security, costs and climatic change, the impacts of energy have partly been internalized within the cost of both these drivers, enabling a differentiation to be seen in the market. Whether or not the other environmental practices become internalized will have a bearing on driving these areas forward. How these drivers are packaged together to develop the most appropriate strategy to meet a client's objectives with their buildings, and how they are deployed, are critical to the success of the refurbishment (Shah, 2012). Therefore, sustainable building refurbishment is the right direction to go.

\subsection{Sustainable Refurbishment and Stakeholders}

Although the demand for sustainable buildings has become a trend (Horman et al. 2006), the focus has predominantly been placed on new buildings. According to Chow (2003), it is always important to upgrade the old buildings to satisfy the new "green or sustainable" 
initiatives, such as refurbishing existing buildings to reduce greenhouse gas emissions is important in meeting Australian government aspirational targets (Hertzsch et al. 2011). Mickaityte et al. (2008) add that sustainable development principles have reached many spheres of human activities, buildings refurbishment cannot be an exemption. Sustainable upgrading the building facilities supports excellent opportunities to reduce energy consumption in buildings as well as encourages other sustainability principles implementation, such as occupants' wellbeing, environment protection, rational resources use and stakeholders groups' awareness.

Regarding evaluation, Sijtsma et al. (2011) state that the four key elements in the sustainability evaluation is to adopt a long-term view, concern the global perspective, include at least three crucial components: economic, social and environmental and take the stakeholders' understanding and accountability. Therefore, there is a need to involve stakeholders in sustainable refurbishment. As stated by Wilkinson et al. (2009), the stakeholders involved in a sustainable refurbishment to existing commercial building could include developers, investors, producers, marketers, regulators/policy makers and occupants. These key stakeholders must involve in the decision-making for sustainable refurbishment of building facilities, and this research study will deliberatively collect the views from these stakeholders.

\subsection{Benefits of a Sustainable Refurbishment}

Wilkinson et al. (2009) contend that social, environmental and economical are the key deciding attributes to be considered when addressing the need for sustainable refurbishment an existing commercial building. Therefore, when considering the feasibility of sustainably upgrading and refurbishing, the environmental benefits may need to be justified by the costs versus a new development. As stated by Shipley et al. (2006), upgrading an existing building for reuse can represent a $10-12 \%$ cost saving as opposed to a constructing new building. The saving is directly related to the reduced construction works required, combined with the ability to maximize the potential of existing building components, such as external walls, slabs, etc. There are also significant savings that are achievable in the operational energy costs of a sustainable building. A case study conducted by Madew (2006) showing a $60 \%$ saving in water and energy consumption in a sustainable building as opposed to an existing building, this therefore could reduce operational costs from $\$ 120$ to $\$ 60$ per square meter.

On the other hand, when considering the operation cost reduction through sustainability; Kats and Capital (2003) conclude that sustainable features lower water/waste and energy costs, lower emission and environmental costs, lower maintenance and operation costs, increased productivity and occupant health. The author further suggested that it could reduce the overall operational cost by $\$ 50$ to $\$ 70$ per square foot compared with a non-sustainable building. It is also worth to note that the link between sustainably upgraded buildings and increased investment returns is always an attractive to client. Horman et al. (2006) state that there is growing demand for high performance sustainable buildings. As suggested Beattie (2009), by sustainably upgraded and/or refurbished buildings achieve overall higher rents, a reduction in operational energy costs, reduced building vacancies and a longer life span of the investment. In fact, extending the useful life of an existing commercial building leads to a lowering in material, transport and energy consumption and pollution, which has large environmental benefits over demolish/rebuild projects (Bullen 2007). As stated by Victoria and Kador Group (2010), the environmental benefits of sustainably upgrading existing commercial buildings provide considerable advantages to the buildings occupants. On the other hand, the trend of using natural renewable materials also forms the beneficial criteria for considerations in regards to new materials selection in a sustainable refurbishment (Kibert 2012). Especially, this is important for minimizing the embodied energy contributed to the existing structure. In the material selection process, consideration needs to be given to the embodied energy and the associated carbon footprint that will be added to the existing structure from the selected material.

From an occupant perspective, according to Victoria and Kador Group (2010), increased business performance stems from a more productive, healthy work environment; this initiative adds positive financial consideration for sustainable refurbishments. Overall the degree of financial benefit that can be achieved through a sustainable refurbishment is more than justified and presents a financially positive argument for existing commercial buildings.

In summary, benefits of a sustainable refurbishment include: environment [i.e. energy efficiency, emission reduction, waste reduction, water usage reduction]; economical in term of costs [i.e. improved building value, better rental returns, operational cost, extended building life span]; social in term of building occupants [i.e. improved productivity, better health and wellbeing]. and figures.

\section{Research Design and Data Collection}

This research study aims to not only explore the perceptions and understandings the theories for sustainable refurbishment, but also to collect the views of the building professions to validate the theories and know their appreciation of sustainably refurbishment of existing commercial buildings. In order to capture the data, a questionnaire survey was developed based around the literatures review. It is because, the selection of a survey to achieve results was seen as one of the most effective way to gather feedback, as it is a well-used tool in social science research topics (Babbie 2008). In doing so, the questionnaire 
includes both scaled and open questions that allow for answers to be ranked and detailed information to be gather through comments. This structure aimed to achieve both quantitative and qualitative results, which were not only seen to be more appealing to the participants but also allowed for a differing set of analyzed results. (Babbie 2008; Burton \& Steane 2004).

The targeted participants include, project managers, consultants, architects, developers, building owners or any professional with a solid understanding of sustainability and construction. This diverse selection of participants was important to ensure the data collected demonstrated different views and skill sets involved in sustainable building projects. The population of the questionnaire was sent to 10 professionals that specialized in sustainable construction and adaptive reuse of existing commercial buildings. From these selected participants, six responded to the questionnaire survey therefore achieving a response rate of $60 \%$.

\section{Survey Results and Discussions}

The first part of the research is to ask participants' to rank the benefits of sustainable refurbishments, and the second part is about how to make sustainable refurbishments beneficial.

\subsection{Quantitative Research for Benefits of Sustainable Refurbishments}

Initially, all respondents agreed that sustainable refurbishments are appreciated in the building industry and facilities management. When considering the importance of sustainable refurbishments, $83 \%$ of respondents believed it to be a growing trend.

Regarding potential benefits, participants were asked to rank the importance of environment, costs and building occupants. According to the respondents, environmental benefits of a sustainable refurbishment overall resulted in positive feedback and the order of benefits is energy efficiency, building waste reduction, emissions reduction, and water usage.

Regarding economical benefits, the cost benefits to the building value showed $50 \%$ of respondents agreeing there would be a 'good' improvement after a sustainable refurbishment. Operational cost results were split into 'good' and 'excellent' through a sustainable refurbishment to the existing commercial building. The operational cost benefits are a direct result of the positive impact seen in the environmental factors as improvements to the buildings "green" efficiency result in lower running costs.

Regarding social benefits to the building occupants, $50 \%$ of respondents suggested an 'excellent' result after a sustainable refurbishment. The respondents overall agreed that a sustainable building would also create a more productive environment that attracted better staff and improve health and wellbeing.
Overall all results had the majority of respondents identifying the benefits that could be achieved through sustainably refurbishment to an existing commercial building and social benefits are most obvious.

\subsection{Qualitative Research for Benefits of Sustainable Refurbishments}

Further to the ranking questions, participants were asked to advise other benefits for sustainable refurbishment, decision factors and process for refurbishment, as well as suggestion for sustainability strategy.

\subsubsection{Intangible Benefits for Sustainable Refurbishment}

Respondents have identified the intangible social benefits for sustainable refurbishment is important. A good internal working environment as suggested by respondents increases the health and wellbeing of building occupants. There is a link to reduce sick leave among occupants leading to a higher level of work output. There is also the increased happiness among occupants that improves the working environment and encourages increased productivity and higher staff retention. As with productivity, a high staff retention rate is a crucial business success driver that adds considerable benefit to an organization. The flow on effect is organizations can train and develop employees to achieve a higher level of workout and as suggested by a participant reduces administration costs.

\subsubsection{Decision Factors of Refurbishment}

Although respondents ranked social benefits are most obvious in the refurbishment, the majority of respondents suggested that the most important decision factor was the economical aspects. This was based on the fact that the feasibility of the project must be weighed up and comparisons need to be drawn between the upgrading cost and potential rental benefits. Closely behind the economical reasons to sustainably refurbish were the social factors, which some respondents believed to be the most important. The importance of the social appreciation for a sustainable refurbishment within the community as well as the employee's health and wellbeing was the most important consideration after the economical feasibility.

A perception among respondents was that the environmental considerations were seen as a benchmark and the other factors are what separated a successful project and rationalized the need to upgrade the existing commercial building. The technological considerations ranked the lowest in the hierarchy. As overall respondents agreed that although the economical considerations should be ranked number one in the hierarchy the social and technological factors had a very close impact on the economic feasibility of the project.

\subsubsection{Stakeholders and Decision Making Process}

Closely linked to the importance placed on the economic considerations had the majority of respondents agreeing that 
the developers, building owners and investors were the three most important stakeholders involved. One participant suggested that due to the developers, building owners and investors having control over the financing of the project, all decision making power is held solely by the three parties.

From the respondents' responses, the initial decision process was suggested to begin with the important stakeholders making the decision to consider a sustainable refurbishment. The project manager and end-users would then begin to establish a list of sustainability recommendations. It would then be the task of the design consultants in conjunction with quantity surveyors to put a cost estimate together showing the additional costs as per the green recommendations. The final stage is for the developers, building owners and investors to make a business decision based on the potential benefits versus the cost feasibility.

Respondents further suggested that three precedent strategies in sustainable refurbishments to materialize the benefits:

Reusing Building Elements: Manipulation or reuse through modification is an important part of preserving the maximum amount from the existing commercial building elements. As suggested by a participant, the internal fit out of the building can be reused in a different form through an upgrade. Partition walls and ceilings can often remain or be modified to suit the needs of the new upgraded buildings purpose. This concept of modifying current elements leads to further benefits in environmental benefits and cost savings as it reduces the need for new materials and therefore transportation. With the consideration of safety and longevity all respondents agreed that the majority of building elements could be preserved in an existing commercial building.

Applying Sustainable Techniques: Respondents agreed that, for example, lighting and the use of natural lighting are one of major areas of benefit that could be achieved in an existing structure. Through redesigning a more open floor plan this would not only improve the effectiveness of natural light but also make improvements to passive lighting. One participant suggested the use of natural cross ventilation further reduces the need for heating/cooling loads and further add to user comfort.

Using New Materials and adopting New Technologies: There is still a need to use new materials and technologies to ensure the upgraded building is fit for the purpose in which it is to be used. When considering the material selection, the most common response given by all respondents was to source low embodied energy products. A few responses from respondents agreed that new products should emit low or zero volatile organic compounds and formaldehydes as both can have negative environmental effects as well as the buildings occupants. A response also suggested the need to minimize the use of PVC through an upgrade due to the negative impact associated throughout its life span. However, consideration must also be given to the any new technologies required in an existing commercial building to ensure it meets the standards of the current new buildings. Respondents identified the potential benefit to be gained through building controls, which could be applied to lighting, air handling, etc. The use of integrated control could also be combined with operation input and feedback, which would help to maximize the potential gained from the building. A participant also identified the need for longer operating life spans with a lower degree of maintenance required from building technologies to reduce building inefficacy. Much the same as the upgrading process the key to reducing environmental impact and costs is efficiency which needs to be maintained to ensure the maximum potential is gained from the existing commercial building.

\section{Conclusion}

The aim of building maintenance is to preserve the building in its initial effective state and this must be started from building maintenance at organizational strategic level. If the completed building facilities are not managed and maintained properly, they cannot perform as intended. Therefore, building maintenance and refreshment are required to upkeep the facilities in best operation conditions. There is a need to consider the facilities management and building maintenance strategies in advance, and it must be part of the core business decisions.

In fact, building facilities must always be maintained to an acceptable condition and every part of the facilities must be refurbished and/or upgraded to sustain its utilities and value according to the new building and environmental regulations. Sustainable refurbishment means to provide a healthier environment such as less energy consumption, lower greenhouse gas emissions, rational resources use and advanced technologies. The existing commercial building stock holds enormous potential for improvements and it offers building owner a strategic avenue to sustainably refurbish the facilities which will benefit the society and community.

From the literature reviews, the importance of building maintenance strategy has been confirmed. Then, key stakeholders in sustainable refurbishment, including developers, investors, producers, marketers, regulators/policy makers and occupants, has been identified. It is also worth to note that the key factors affecting sustainable refurbishment for commercial building include social, environmental, economical considerations. Benefits of refurbishment commercial building are energy efficiency, emission reduction, waste reduction, water usage reduction [environmental benefits], improved building value, better rental returns, reduced operational cost, extended building life span [economical benefits], improved productivity, health and wellbeing [social benefits].

However, maximum benefit can only be obtained subject to thorough consideration prior to refurbishing the facilities. 
Therefore, understanding the factors and perceived benefits from theories does not suffice for stakeholders for decision. There is a need to comprehend each sustainable criterion and consideration in order to ensure the maximum benefit is achieved from a sustainable refurbishment. This research study therefore provides quantitative and qualitative views from the data collected from building professions.

From the quantitative research, all respondents agreed that sustainable refurbishments are appreciated in the building industry and facilities management. Amongst the potential environment, economical and social benefits, building professions rank social benefits are most obvious. In order to validate the feasibility of sustainably upgrading, a further round of qualitative research has been conducted. Respondents identified the intangible social benefits for sustainable refurbishment by improving productivity, because a good internal working environment helps to reduce sick leave among occupants leading to a higher level of work output. Respondents also believe that developers, building owners and investors are important stakeholders. When they make the decision to a refurbishment, the most important decision factor is the economical aspects which have a very close link with social and technological criterion of the project that stakeholders must consider in the decision process. Therefore, project manager and end-users would involve in sustainability recommendations. Then, design consultants and quantity surveyors will be called upon to estimate the additional costs for such green recommendations.

Overall, professionals support the sustainable refurbishment perspective because they can perceive the tangible and intangible benefits for the sustainable strategy over traditional methods. The earlier provides a better solution and energy-efficient building, and not only ensures efficient and effective management of existing building facility but also directly enhances the building value.

Finally, respondents also suggested three precedent strategies in sustainable refurbishments to materialize the benefits. These include reusing building elements, application of sustainable techniques and using new materials and adopting new technologies.

Overall this paper has provided a strong discussion of literatures and contribution of primary research to the sustainable refurbishment of existing commercial buildings. Further research studies should include facilities managers and property managers from the commercial building operation perceptive.

\section{Acknowledgements}

Thank and acknowledge the research input by $\mathrm{Mr}$. Christopher Lee.

\section{REFERENCES}

[1] Ali, A-S, Kamaruzzaman, S-N, Sulaiman, R \& Peng, YC 2010, 'Factors affecting housing maintenance cost in Malaysia', Journal of Facilities Management, vol. 8, no. 4, pp. 285-98.

[2] Amani, N, Ali, NM, Mohammed, AH \& Samat, RA 2012, 'A survey on the implementation of facilities maintenance management system of building in Iran', Malaysian Journal of Civil Engineering, vol. 24, no. 1, pp. 85-95.

[3] Babbie, ER 2008, The basics of social research, 4th edn, Wadsworth Publishing Company.

[4] Beattie, M 2009, 'Retro-greening - time for a tune-up', Property Australia, retrieved 12 Oct 2010, database.

[5] Bullen, PA 2007, 'Adaptive Reuse and Sustainability of Commercial Buildings', Facilities, vol. 25, no. 1/2, pp. 20-31.

[6] Burton, S \& Steane, P 2004, Surviving Your Thesis, Taylor and Francis, Hoboken.

[7] Chanter, B \& Swallow, P 2008, Building Maintenance Management, $2^{\text {nd }}$ Edn Blackwell.

[8] Chow, W 2003, 'Fire safety in green or sustainable buildings: Application of the fire engineering approach in Hong Kong', Architectural Science Review, vol. 46, no. 3, pp. 297-303.

[9] Christian, J \& Pandeya, A 1997, 'Cost predictions of facilities', Journal of Management in Engineering, vol. 13, no. 1, pp. 52-61.

[10] De Marco, A, Ruffa, S \& Mangano, G 2010, 'Strategic factors affecting warehouse maintenance costs', Journal of Facilities Management, vol. 8, no. 2, pp. 104-13.

[11] Ding, S \& Itoh, Y 2002, 'Towards the Development of an Integrated Management Procedure: Lifecycle Management System For Construction Project', World Project Management Week, Hongkong.

[12] Fu, C, Kaya, S \& Aouad, MKG 2007, 'The development of an IFC-based lifecycle costing prototype tool for building construction and maintenance: integrating lifecycle costing to $\mathrm{nD}$ modelling', Construction Innovation: Information, Process, Management, vol. 7, no. 1, pp. 85-98.

[13] Gilpin-Jackson, A 2010, 'Strategic asset management for physical infrastructure: Run, repair, refurbish, replace', Master thesis, University of Sierra Leone.

[14] Hertzsch, E, Heywood, C, Piechowski, M \& Rowe, A 2011, 'Aspects of life cycle investing for sustainable refurbishments in Australia', Sustainability in Energy and Buildings, pp. 201-10

[15] Horman, MJ, Riley, DR, Lapinski, AR, Korkmaz, S, Pulaski, MH, Magent, CS, Luo, Y, Harding, N \& Dahl, PK 2006, 'Delivering green buildings: Process improvements for sustainable construction', Journal of Green Building, vol. 1, no. 1, pp. 123-40.

[16] Kats, G \& Capital, E 2003, Green building costs and financial benefits, Massachusetts Technology Collaborative Boston, MA.

[17] Kibert, CJ 2012, Sustainable construction: Green building design and delivery, 3rd edn, John Wiley \& Sons, Hoboken, 
N.J.

[18] Kishk, M, Al-Hajj, A, Pollock, R, Aouad, G, Bakis, N \& Sun, M 2003, 'Whole life costing in construction-A state of the art review', RICS Foundation Research Papers, vol. 4, no. 18, pp. $1-39$.

[19] Kofoworola, OF \& Gheewala, SH 2008, 'Environmental life cycle assessment of a commercial office building in Thailand', The International Journal of Life Cycle Assessment, vol. 13, no. 6 , pp. 498-511.

[20] Lai, AW \& Pang, PS 2010, 'Measuring performance for building maintenance providers', Journal of Construction Engineering and Management, vol. 136, no. 8, pp. 864-76.

[21] Lai, J 2010, 'Operation and maintenance budgeting for commercial buildings in Hong Kong', Construction Management \& Economics, vol. 28, no. 4, pp. 415-27.

[22] Lee, H \& David, S 2008, 'Overview of maintenance strategy, acceptable maintenance standard and resources from a building maintenance operation perspective', Journal of Building Appraisal, vol. 4, no. 4, pp. 269-78.

[23] Lee, HY \& David, S 2009, 'Strategic and operational factors' influence on the management of building maintenance operation processes in sports and leisure facilities, Hong Kong', Journal of Retail \& Leisure Property, vol. 8, no. 1, pp. 25-37.

[24] Madew, R 2006, 'Making sense of green buildings', Property Australia, retrieved 12 Oct 2010, database.

[25] Matthews, S 2007, 'CONREPNET: Performance-based approach to the remediation of reinforced concrete structures: Achieving durable repaired concrete structures', Journal of Building Appraisal, vol. 3, no. 1, pp. 6-20.

[26] McLean, IW 2012, Why Australia Prospered: The Shifting Sources of Economic Growth, Princeton University Press.

[27] Mickaitytè, A, Zavadskas, EK, Kaklauskas, A \& Tupennaite, L 2008, 'The concept model of sustainable buildings refurbishment', International Journal of Strategic Property Management, vol. 12, no. 1, pp. 53-68.

[28] Narayan, V 2012, 'Business performance and maintenance: How are safety, quality, reliability, productivity and maintenance related?', Journal of Quality in Maintenance Engineering, vol. 18, no. 2, pp. 183-95.

[29] Olanrewaju, AA, Khamidi, MF \& Idrus, A 2011, 'Validation of Building Maintenance Performance Model for Malaysian Universities', World Academy of Science, Engineering \& Technology, no. 56, pp. 726-30.

[30] Rojahn, C, Mayes, RL, McLane, TR, Holmes, W, Dowty, S,
Eguchi, RT, Harris, J, Petak, W, Rojahn, C \& Stillwell, K 2011, 'Proceedings for a Workshop on a Rating System for the Earthquake Performance of Buildings'.

[31] Róka-Madarász, L 2011, 'Performance Measurement for Maintenance Management of Real Estate', Acta Polytechnica Hungarica, vol. 8, no. 1, pp. 161-72.

[32] Shah, S. (2012). Sustainable Refurbishment. Somerset, NJ, USA: Wiley.

[33] Shipley, R, Utz, S \& Parsons, M 2006, 'Does adaptive reuse pay? A study of the business of building renovation in Ontario, Canada', International Journal of Heritage Studies, vol. 12, no. 6 , pp. 505-20.

[34] Sijtsma, F, Heide, C \& Hinsberg, Av 2011, 'Biodiversity and Decision-Support: Integrating CBA and MCA', in A Hull, ER Alexander, A Khakee \& J Woltjer (eds), Evaluation for Participation and Sustainability in Planning, 1 edn, Routledge, Hoboken.

[35] Tran, V. T., Yang, B.-S., Oh, M.-S., \& Tan, A. C. C. (2008). Machine condition prognosis based on regression trees and one-step-ahead prediction. Mechanical Systems and Signal Processing, 22(5), pp. 1179-93.

[36] Victoria_and_Kador_Group 2010, Employee productivity in a sustainable building. :, Sustainability Victoria, Melbourne, Australia.

[37] Wang, L., Chu, J., \& Wu, J. (2007). Selection of optimum maintenance strategies based on a fuzzy analytic hierarchy process. International Journal of Production Economics, 107(1), pp. 151-63.

[38] Wileman, G 2007, The challenge of strategic leadership, Strategic Leadership of Change in Higher Education: What's New?

[39] Wilkinson, S, James, K \& Reed, R 2009, 'Delivering sustainability through the adaptive reuse of commercial buildings: the Melbourne CBD challenge', in PRRES 2008: Proceedings of the Pacific Rim Real Estate Society 15th Annual Conference, pp. 1-19.

[40] Wilkinson, SJ, James, K \& Reed, R 2009, 'Using building adaptation to deliver sustainability in Australia', Structural survey, vol. 27, no. 1, pp. 46-61.

[41] Yiu, CY 2007, 'Building depreciation and sustainable development', Journal of Building Appraisal, vol. 3, no. 2, pp. 97-103.

[42] Zawawi, EMA, Kamaruzzaman, SN, Ali, AS \& Sulaiman, R 2010, 'Assessment of building maintenance management in Malaysia: Resolving using a solution diagram', Journal of Retail \& Leisure Property, vol. 9, no. 4, pp. 349-56. 